OPEN ACCESS

Edited by:

Ralph Panstruga,

RWTH Aachen University,

Germany

Reviewed by:

Richard Belanger,

Université Laval, Canada

Alejandro Perez-Garcia,

University of Malaga,

Spain

*Correspondence:

Maggie Levy, Department of Plant

Pathology and Microbiology, The

Robert H. Smith Faculty of Agriculture,

Food and Environment, The Hebrew

University of Jerusalem, Lautreman

Building, Herzel St. No. 1, PO Box 12,

Rehovot 76100, Israel

maggie.levy@mail.huji.ac.il

Specialty section:

This article was submitted to

Plant-Microbe Interaction, a section of

the journal Frontiers in Plant Science

Received: 13 November 2014

Accepted: 18 February 2015

Published: 11 March 2015

Citation:

Gafni A, Calderon CE, Harris $R$, Buxdorf K, Dafa-Berger A, Zeilinger-Reichert $E$ and Levy $M$

(2015) Biological control of the cucurbit powdery mildew pathogen Podosphaera xanthii by means of the epiphytic fungus Pseudozyma aphidis and parasitism as a mode of action.

Front. Plant Sci. 6:132

doi: 10.3389/fpls.2015.00132

\section{Biological control of the cucurbit} powdery mildew pathogen Podosphaera xanthii by means of the epiphytic fungus Pseudozyma aphidis and parasitism as a mode of
action

Aviva Gafni ${ }^{1}$, Claudia E. Calderon ${ }^{1}$, Raviv Harris ${ }^{1}$, Kobi Buxdorf ${ }^{1}$, Avis Dafa-Berger ${ }^{1}$, Einat Zeilinger-Reichert ${ }^{2}$ and Maggie Levy ${ }^{1 *}$

${ }^{1}$ Plant Pathology and Microbiology, Hebrew University of Jerusalem, Jerusalem, Israel, ${ }^{2}$ The Interdepartmental Equipment Facility, The Robert H. Smith Faculty of Agriculture, Food and Environment, Hebrew University of Jerusalem, Jerusalem, Israel

Epiphytic yeasts, which colonize plant surfaces, may possess activity that can be harnessed to help plants defend themselves against various pathogens. Due to their unique characteristics, epiphytic yeasts belonging to the genus Pseudozyma hold great potential for use as biocontrol agents. We identified a unique, biologically active isolate of the epiphytic yeast Pseudozyma aphidis that is capable of inhibiting Botrytis cinerea via a dual mode of action, namely induced resistance and antibiosis. Here, we show that strain $L 12$ of $P$. aphidis can reduce the severity of powdery mildew caused by Podosphaera xanthii on cucumber plants with an efficacy of $75 \%$. Confocal and scanning electron microscopy analyses demonstrated $P$. aphidis proliferation on infected tissue and its production of long hyphae that parasitize the powdery mildew hyphae and spores as an ectoparasite. We also show that crude extract of $P$. aphidis metabolites can inhibit $P$. xanthii spore germination in planta. Our results suggest that in addition to its antibiosis as mode of action, $P$. aphidis may also act as an ectoparasite on $P$. xanthii. These results indicate that $P$. aphidis strain L12 has the potential to control powdery mildew.

Keywords: dimorphism, biocontrol, powdery mildew, phytopathogens, parasitism

\section{Introduction}

Plant pathogens challenge our efforts to maximize crop production. Fungi, bacteria and other pathogens attack various parts of crop plants, inducing diseases that reduce the plant's growth rate, suppress plant development and reduce yield. Agronomists use chemical-based pesticides to control the spread of pathogens and pests and help ensure stable and prosperous agricultural systems. Nevertheless, constant selective pressures from multiple applications has led to the development of pathogens and pests that are resistant to chemical pesticides and consequently efforts are being made to develop novel techniques and tools to control these pests and pathogens (Denholm and Rowland, 1992; Leroux et al., 2002). Among these tools, fungal biocontrol agents have attracted much attention as a viable and important alternative to conventional pesticides. Biological control 
may involve one or a combination of mechanisms, such as antibiosis, mycoparasitism, competition and the induction of generalized resistance in the host plant (Elad and Freeman, 2002; Shoresh et al., 2010). These mechanisms can hinder pathogen growth and development, thereby reducing disease. The complex modes of action of biocontrol agents, unlike those of chemical agents, reduce the likelihood of pathogens developing resistance to these agents, which increases the appeal of biocontrol agents as an alternative to conventional chemical products in the battle against pests and pathogens.

Epiphytic yeasts that colonize different plant surfaces (Pusey et al., 2009; Fernandez et al., 2012) are thought to possess biocontrol activity and to provide a natural barrier against certain plant pathogens (Avis et al., 2001; Urquhart and Punja, 2002; Bleve et al., 2006; Jacobsen, 2006; Robiglio et al., 2011). Epiphytes usually produce extracellular polysaccharides, which are thought to help them survive on aerial plant surfaces that are exposed to the elements. Phylloplane yeasts can also metabolize a wide variety of nutrient sources and tolerate a variety of chemical-based fungicides (Barnett et al., 2000; Buck and Burpee, 2002), characteristics which could potentially contribute to their utility as biocontrol agents.

The genus Pseudozyma is a small group of yeast-like fungi classified among the Ustilaginales (Boekhout, 1995). They are mostly epiphytic or saprophytic and they are non-pathogenic to plants, animals and insects (Avis and Belanger, 2002). Pseudozyma rugulosa and Pseudozyma flocculosa have both been reported to exhibit biological activity against the different powdery mildews with which they are associated (Dik et al., 1998; Hammami et al., 2010, 2011) (for review see Kiss, 2003). P. flocculosa, for example, does not penetrate powdery mildew cells, but has been found to secrete an unusual fatty acid that has an antibiotic effect against powdery mildew and other pathogens (Hajlaoui et al., 1994; Benyagoub et al., 1996; Avis and Belanger, 2001; Avis et al., 2001). Recently the genome and transcriptome of the biocontrol agent $P$. flocculosa was published and compared to the related plant pathogen Ustilago maydis and other Ustilaginales pathogens (Lefebvre et al., 2013). Genome comparison demonstrated high similarity of genomes, including the matingtype loci, meiosis loci and pathogenicity components, suggesting $P$. flocculosa used to be a virulent smut pathogen. Furthermore, it was shown that $P$. flocculosa has lost a subset of secreted effectors reported to influence virulence while acquiring other genes coding for secreted proteins, not found in the pathogenic fungi, that probably contribute to its biocontrol nature (Lefebvre et al., 2013). In agreement with these findings, the genome and transcriptome of $P$. antarctica, that did not demonstrate biocontrol ability against powdery mildew (Avis et al., 2001), shares a high degree of syntany to the pathogenic fungus $U$. maydis. However, the transcriptome analysis reveals significant differences regarding pathogenicity and metabolism, indicating $P$. antarctica has an oleaginous nature which is relevant to its non-pathogenic characteristics (Morita et al., 2013b, 2014).

Pseudozyma aphidis is a close relative of the powdery mildew biocontrol agent $P$. rugulosa (Begerow et al., 2000). P. aphidis was first isolated from aphid secretions (Henninger and Windisch, 1975) and later identified on plant surfaces as well (Allen et al.,
2004). Recently the sequence of $P$. aphidis isolate DSM70725 that was isolated from aphid secretions was published (Lorenz et al., 2014). Previous studies on another P. aphidis strain that was also isolated from aphid secretions (isolate CBS517.83) indicated that this species does not produce any unique fungitoxic fatty acids (Avis and Belanger, 2001) and is not associated with the collapse of powdery mildew colonies [Podosphaera xanthii formerly Sphaerotheca fuliginea (Schlechtend.:Fr.) Pollacci].

We recently reported on a unique active isolate of $P$. aphidis that was identified on the surface of strawberry leaves in association with powdery mildew collapse (designated isolate L12). We demonstrated this isolate's activity against Botrytis cinerea colonization and spread on tomato (Solanum lycopersicum) and Arabidopsis thaliana plants. That observed biocontrol effect was based on a dual mode of action: antibiosis and induced resistance (Buxdorf et al., 2013a,b). The induced resistance was found to be both SA/NPR1- and JAR1/EIN2-independent (Buxdorf et al., 2013a,b).

Powdery mildew is the most common disease of cucurbits and a serious threat in many countries. P. xanthii is considered to be the main causal agent of powdery mildew on cucurbits, one of the most important limiting factors for cucurbit production (Bélanger et al., 2002; Perez-Garcia et al., 2009). The constant fungicide application in the field to control this pathogen has led to the development of resistance to various chemicals, thereby reducing the effectiveness of these treatments (McGrath, 2001; Hollomon et al., 2002). Thus, efforts are being made to develop novel techniques to control powdery mildew in the field.

Here, we present a potentially efficient biological control agent against cucurbit powdery mildew that relies on the biologically active $P$. aphidis strain (isolate L12). We demonstrate in the current work the ability of this isolate to antagonized powdery mildew on cucumber plants, using parasitism and antibiosis as modes of action.

\section{Materials and Methods}

\section{Propagation of $\boldsymbol{P}$. aphidis and Pathogens}

Pseudozyma aphidis strain L12 was maintained on potato dextrose agar (PDA; Difco, France) at $25^{\circ} \mathrm{C}$. An indigenous population of Podosphaera xanthii was maintained on squash (Cucurbita maxima) plants under field conditions.

\section{Propagation of Plants}

Cucumber (Cucumis sativus cv. Saphi) plants were grown at $25^{\circ} \mathrm{C}$ under $40 \%$ relative humidity in the greenhouse.

\section{Fluorescence Microscopy}

A GFP-labeled $P$. aphidis (see Supplementary Figure 1 and Supplementary Methods) was used to visualize colonization of healthy and infected tissue. Ten-day-old cucumber cotyledons were sprayed with either water or GFP-P. aphidis $\left(10^{8}\right.$ cells $/ \mathrm{ml}$ of sterile, deionized water). Three days after treatment the cotyledons were placed on tap water agar medium and then inoculated with $P$. xanthii. Inoculation with $P$. xanthii was done by brushing cucumber cotyledons at several points with a brush that had been 
vigorously rubbed on squash (Cucurbita maxima) leaves that had been intensely colonized by $P$. xanthii.

The inoculated cucumber cotyledons were layered on agar trays and placed in a controlled-environment chamber where they were kept at $22^{\circ} \mathrm{C}$ at $80-90 \%$ relative humidity and under fluorescent and incandescent light with a photofluency rate of approximately $120 \mu \mathrm{mol} / \mathrm{m}^{2} \mathrm{~s}$ and a $12-\mathrm{h}$ photoperiod. Twoseven days after inoculation with $P$. xanthii, the cotyledons were examined with a stereomicroscope (Nikon SMZ 1500) with an epifluorescence attachment (Nikon P-FLA-2). The intensity of the green fluorescence produced by excitation at $488 \mathrm{~nm}$ was measured and a GFP filter was used for visualization (Nikon, GFP-B). Images were taken using a Nikon Ds-Rilcamera and processed with NIS elements BR 3.10 software. Cotyledons were also examined with confocal laser scanning microscope (TCS SP8, Leica) 7 days after inoculation with P. xanthii; GFP was excited using a $488 \mathrm{~nm}$ laser and maximum emission was set at $500 \mathrm{~nm}$. Cucumber cotyledons were also treated with $1 \mathrm{mg} / \mathrm{ml}$ propidium iodide that was excited using a $514 \mathrm{~nm}$ laser and maximum emission was set at $610 \mathrm{~nm}$. The images were analyzed in the LAS AF (Leica) computer program, at a resolution of $1024 \times 1024$ pixels. The experiments were repeated three times.

\section{Inhibition of Powdery Mildew on Cucumber Seedlings}

Two-week-old greenhouse-grown $\left(25^{\circ} \mathrm{C}\right.$ and $40 \%$ relative humidity) cucumber seedlings (with two true leaves) were sprayed with $P$. aphidis cells suspended in water $\left(10^{8}\right.$ cells $\left./ \mathrm{ml}\right)$ or water $(n=10) 3$ days before they were inoculated with $P$. xanthii. Inoculation with $P$. xanthii was performed by brushing cucumber leaves with a brush that had been vigorously rubbed on squash (Cucurbita maxima) leaves that were intensely colonized by $P$. xanthii. Infection severity was scored 11,12 , and 16 days post-inoculation by evaluating the percentage of the infected area on each of the first two leaves. The experiment was concluded after 16 days when the first leaf of the control treatment was fully coved with powdery mildew. Percentage of powdery mildew coverage (PMC) was estimate and disease severity was scored using the 12-grade scale described by Horsfall and Barratt (1945) with minor modifications: $0=0 \%, 1=0-3 \%, 2=3-6 \%, 3=6-$ $12 \%, 4=12-25 \%, 5=25-50 \%, 6=50-75 \%, 7=75-87 \%$, $8=87-94 \%, 9=94-97 \%, 10=97-100 \%, 11=100 \%$ disease. A mean disease-severity index value (DSI) was calculated for each treatment by adding up the scores of the 20 leaves in the treatment and then expressing that sum as a percentage using the formula described by Raupach et al. (1996): Disease Severity Index $=\left[\sum\right.$ (rating no. $\times$ no. of plants in rating $\left.) \times 100 \%\right] /($ total no. of plants $\times$ highest rating). Biocontrol efficacy was calculated as: Efficacy $=[($ disease rate in control - disease rate in treatment)/disease rate in control $] \times 100$. The entire experiment was performed three times with similar results.

\section{Scanning Electron Microscopy}

For scanning electron microscopy (SEM), P. aphidis-treated and powdery mildew-inoculated cucumber cotyledons were collected 1-4 days after inoculation and fixed with glutaraldehyde using standard protocols (Weigel and Glazebrook, 2002). Samples were mounted on aluminum stubs and sputter-coated with AU-Pd. SEM was performed using a Jeol JEM 5410 at $20 \mathrm{kV}$.

\section{Transmission Electron Microscopy}

For transmission electron microscopy (TEM), cucumber cotyledons were treated with $P$. aphidis inoculated with $P$. xanthii 3 days later, and collected 8 days post-inoculation and processed using a standard protocol (Chuartzman et al., 2008). Epon-embedded samples were sectioned using a diamond knife on an LKB 3 microtome (Leica, Bensheim, Germany) and ultrathin sections $(80 \mathrm{~nm})$ were collected onto $200 \mathrm{Mesh}$, thin bar copper grids. The sections on grids were sequentially stained with Uranyl acetate and Lead citrate for $10 \mathrm{~min}$ each and observed with a Technai T12 TEM $100 \mathrm{kV}$ (Phillips, Eindhoven, the Netherlands).

\section{Antibiosis Assays Using Crude Extract of $P$. aphidis Metabolites}

Metabolites were extracted from $P$. aphidis cells using ethyl acetate. One and a half liters of PDB medium in a 3-1 Erlenmeyer flask were inoculated with two $1-\mathrm{cm}^{2}$ blocks of PDA carrying mycelia and/or spores of $P$. aphidis and grown for 10 days at $27^{\circ} \mathrm{C}$, in dark with constant agitation at $150 \mathrm{rpm}$. We then spun down the fungal cells $(5 \mathrm{~min}$ at $7000 \mathrm{rpm})$ and extracted them with a 3-l of ethyl-acetate. The ethyl-acetate fraction was collected and evaporated in a rotor evaporator (Buchi, Flawil, Switzerland) at $42^{\circ} \mathrm{C}$ (Paz et al., 2007). Evaluation of the inhibitory effect of the metabolites extracted from $P$. aphidis on $P$. xanthii conidia germination was carried out using cucumber cotyledons from 1 -week-old plants. Cotyledons disks (15 $\mathrm{mm}$ in diameter) were disinfected with $0.1 \% \mathrm{NaOCl}(\mathrm{w} / \mathrm{v})$ for $2 \mathrm{~min}$, and rinsed twice in sterile distilled water. The crude extract $(200 \mathrm{mg} / \mathrm{ml}$ in ethylacetate) was diluted with distilled water $(1: 15 \mathrm{v} / \mathrm{v})$ and poured into sterile six-well plates. Distilled water and an ethyl acetate diluted in distilled water $(1: 15 \mathrm{v} / \mathrm{v})$ were used as controls. The cotyledon disks were placed in these dilutions upside down and incubated at room temperature for $10 \mathrm{~min}$. After incubation, the disks were transferred onto solid medium (40 g sucrose, $30 \mathrm{mg}$ benzimidazole, $10 \mathrm{~g}$ agar, $1-1$ distilled water) in $5 \mathrm{~cm}$ diameter Petri dishes, and the upper side of the disks was inoculated with conidia of $P$. xanthii with a brush. After $24 \mathrm{~h}$ of incubation $\left(22^{\circ} \mathrm{C}\right.$ and $16 \mathrm{~h}$ of daylight), disks were cleared in boiling absolute ethanol for $20 \mathrm{~min}$ in a water bath, followed by a final wash in glycerol: lactic acid: water $(1: 1: 1 \mathrm{v} / \mathrm{v})$ overnight. The disks were then incubated for $2 \mathrm{~min}$ in aniline blue $(0.2 \%)$ followed by rinsing in distilled water, and then examined under a bright-field microscope. The percentage of spore-inhibition was calculated in relation to untreated control with distilled water. Spore germination in water ranged between 98 and 100\%. For each experiment the means of the distilled water control values were considered as a $100 \%$ germination; all other values were divided by these values and multiplied by a 100 for obtaining the percentage of spore germination. To obtain percentage of spore inhibition the percentage of spore germination was reduced from a 100 .

\section{Chitinase Activity}

To evaluate chitinase activity, $P$. aphidis was grown on tap water agar plates (TWA; $2 \%$ agar) or TWA supplemented with $0.1 \%$ 
(w/v) chitin (Sigma-Aldrich, USA). Colony diameter was measured 8 and 17 days post-inoculation.

\section{Data Analysis}

Student's $t$-test was performed only when data were normally distributed and the sample variances were equal. Significance was accepted at $P<0.05$, as noted in the text or table captions. All experiments described here are representative of at least two independent experiments with the same pattern of results.

\section{Results}

\section{Antagonistic Effect of $P$. aphidis Against Powdery Mildew in Planta}

We first demonstrated the ability of $P$. aphidis to maintain a stable population on cucumber (C. sativus) seedlings. Specifically, we treated 10-day-old seedlings with a $P$. aphidis suspension and monitored the number of CFU appearing over a period of 21 days post-inoculation. The size of the $P$. aphidis remained stable for 18-days on plants maintained under controlled conditions (Supplementary Figure 2). Foliar application of $P$. aphidis $\left(10^{8}\right.$ cells $\left./ \mathrm{ml}\right)$ to cucumber plants did not result in any symptoms of pathogenicity or phytotoxicity, such as chlorosis. Furthermore, following application of GFP-expressing $P$. aphidis (Supplementary Figure 1) to healthy cucumber cotyledons, we observed minor spreading of the green fluorescence cells throughout the cotyledons (Figure 1A). When P. aphidistreated cucumber cotyledons were then inoculated with $P$. xanthii, a stronger, denser and more uniform green fluorescent signal was observed in the inoculated area (Figure 1B), indicating the close association of $P$. aphidis with P. xanthii.

We then tested the ability of $P$. aphidis to control cucumber powdery mildew in vivo. Greenhouse-grown cucumber seedlings (two leaves) were sprayed with $P$. aphidis cells or with water as a control and 3 days later, seedlings were inoculated with $P$. xanthii. The application of $P$. aphidis significantly reduced the severity of powdery mildew disease symptoms on the treated cucumber plants as compared with control untreated infected plants (Table 1). Sixteen days after inoculation, almost all first two leaves of the untreated plants showed close to $100 \%$ coverage with powdery mildews, compared to only $17 \%$ coverage on the treated plants (Table 1 and Supplementary Figure 3). Moreover, the appearance of disease symptoms was delayed by 12 days on the treated plants as compared to the untreated ones. After 11 days, there was $45 \%$ powdery mildew coverage of the untreated leaves, whereas all of the treated leaves were still symptomless (Table 1). Disease severity 12 days post-inoculation was $15 \%$ for plants treated with $P$. aphidis as compared to $88 \%$ for control plants, and 16 days post-inoculation, $31 \%$ for $P$. aphidis-treated plants vs. $98 \%$ for untreated control plants (Table 1). The efficacy of $P$. aphidis treatment was $75 \%$ on day 16 post-inoculation (Table 1).

\section{Morphological Yeast-to-Hypha Transition and Ectoparasitism of $\boldsymbol{P}$. aphidis}

We demonstrated in vitro that $P$. aphidis is a dimorphic yeastlike fungus that grows mainly as a yeast in PDB medium but can form hyphae when grown in different media, such as YMPD

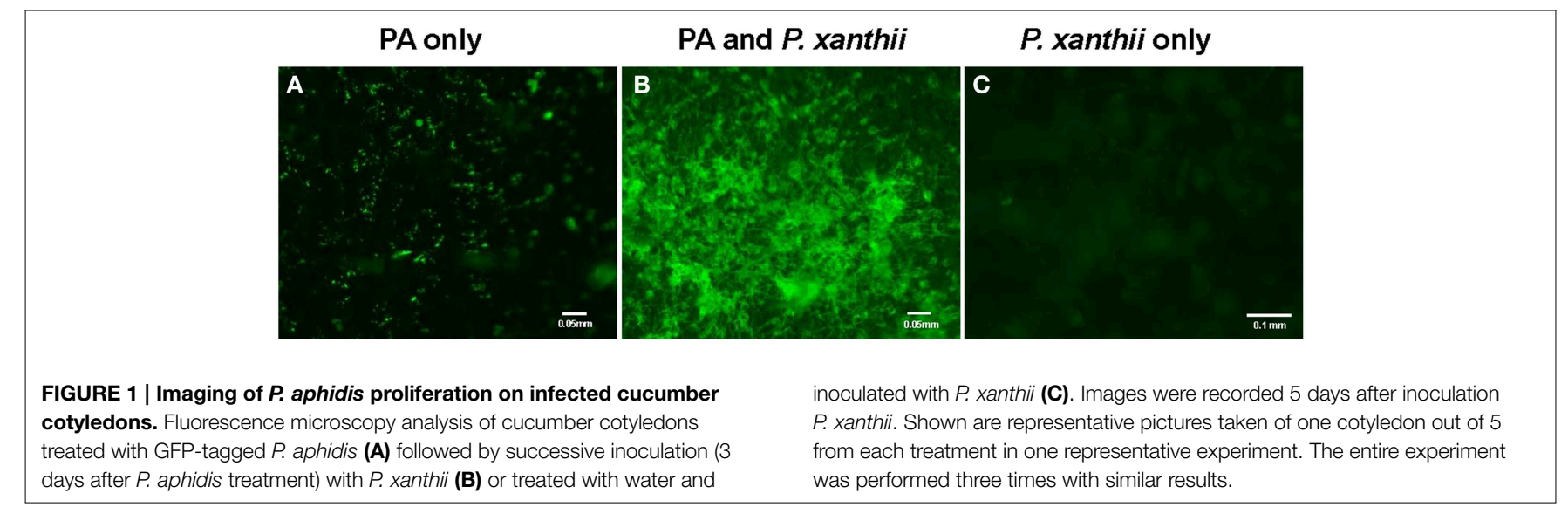

TABLE 1 | Effect of $P$. aphidis treatment on severity of disease symptoms caused by $P$. xanthii.

\begin{tabular}{|c|c|c|c|c|c|c|c|c|c|}
\hline \multirow[t]{2}{*}{ Treatment } & \multicolumn{3}{|c|}{ DSI (\%) } & \multicolumn{3}{|c|}{ PMC (\%) } & \multicolumn{3}{|c|}{ Efficacy (\%) } \\
\hline & 11 dpi & 12 dpi & 16 dpi & 11 dpi & 12 dpi & 16 dpi & 11 dpi & 12 dpi & $16 \mathrm{dpi}$ \\
\hline PA-treated & 0 & 15 & 31 & 0* & $3.2 \pm 1.7^{*}$ & $16.9 \pm 9.1^{*}$ & 100 & 88 & 75 \\
\hline Control & 67 & 88 & 98 & $46.5 \pm 4.7$ & $56.5 \pm 4.7$ & $98.7 \pm 2.5$ & & & \\
\hline
\end{tabular}

Disease severity index (DSI) and P. xanthii average leaf coverage (PMC) were calculated 11, 12 and 16 days post-inoculation (dpi) as described by Raupach et al. (1996). PA, P. aphidis. Means and standard errors of PMC are presented. Means of DSI followed by asterisks is significantly different from inoculated water-treated control according to Student's $t$-test; $P<0.05 ; n=20$ leaves from 10 different plants. 
or MS (Supplementary Figure 4). Using confocal microscopy, we demonstrated the morphological yeast-to-hypha transition (dimorphism) of $P$. aphidis in planta (Figure 2). P. aphidis was mainly in yeast form on uninfected tissue (Figure 2 Left), whereas on $P$. xanthii-infected tissue, it was mainly in hyphal form (Figure 2 Right). SEM revealed that the areas infected with powdery mildew were covered with $P$. aphidis (Figure 3 ), and that the powdery mildew's hyphae were significantly shorter (by $27 \%$, Supplementary Table 1) when they were associated with P. aphidis at infection initiation $2 \mathrm{dpi}$ (Figure 3C). P. aphidis, on the other hand, formed long hyphae that branched when associated with $P$. xanthii and attached to the powdery mildew hyphae by coiling around them as seen by SEM analysis (Figures $\mathbf{3 A}, \mathbf{B}$ ). We observed inhibition of growth and sporulation of powdery mildew on the plants that were treated with $P$. aphidis as compared to control (Figure 3D). We also observed accumulation of extracellular matrix in the area of interaction between $P$. aphidis and powdery mildew, and that the hyphae of $P$. aphidis extending from one powdery mildew hypha to another one were thinner (Figures 3A,B and Supplementary Figure 5). Furthermore, $P$. aphidis behave like an ectoparasite, as demonstrated by confocal and TEM microscopy. We could not detect any GFP fluorescence or $P$. aphidis cells inside the powdery mildew hyphae using confocal microscopy or TEM, respectively (Figures 4, 5 and Supplementary Movies 1,2). TEM analysis of powdery mildew cells associated with $P$. aphidis showed numerous abnormalities: increased vacuolation, deformation of the cell wall and disorganization of the cytoplasm. These abnormalities eventually lead to collapse of the powdery mildew cells (Figure 5). Accumulation of extracellular matrix surrounding $P$. aphidis was also observed (Figure 5).

\section{$P$. aphidis Metabolites Inhibit $P$. xanthii Spore Germination in Planta and Poses Chitinase Activity}

While the precise biochemical nature of the pinkish substance secreted by $P$. aphidis is still unknown, we hypothesized that $P$. aphidis secretes antibiotics and enzymes, such as chitinase, that can inhibit and degrade fungal cell walls. For antibiosis activity, we used $P$. aphidis extract and revealed that crude extract of $P$. aphidis metabolites can almost completely inhibit $P$. xanthii spore germination on intact cucumber cotyledons (Table 2). We also demonstrated that the vast majority of spores that are germinated on extract form a one germination tube and not hypha (Supplementary Figure 6).

For chitinase activity verification we grew $P$. aphidis on TWA plates supplemented with chitin as sole carbon source. On TWA plates supplemented with chitin, $P$. aphidis colony diameter was

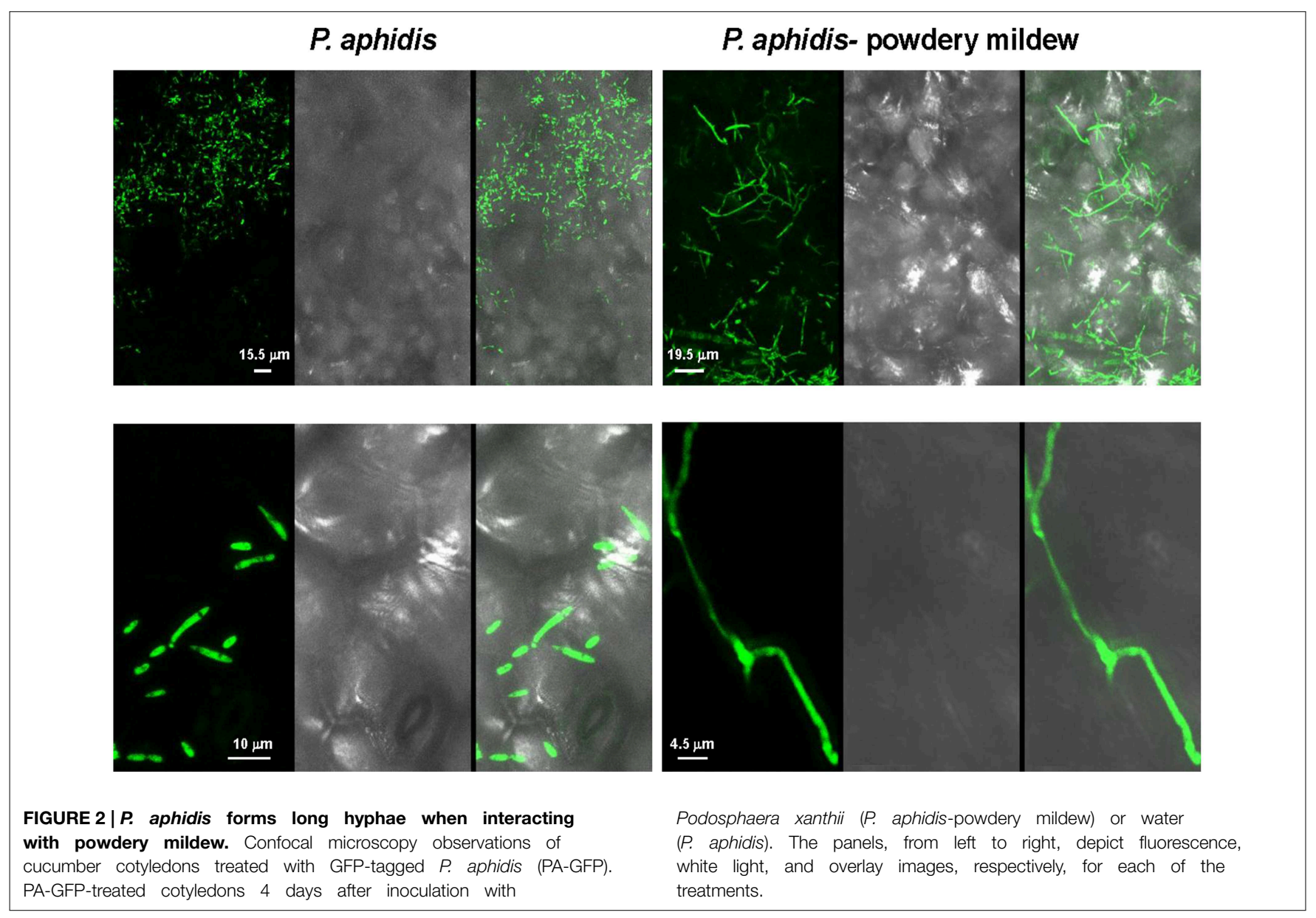


A

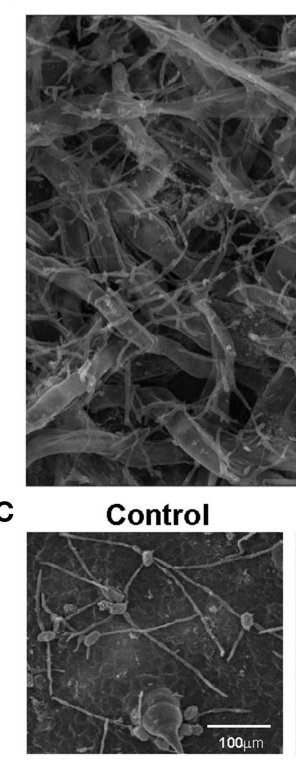

D

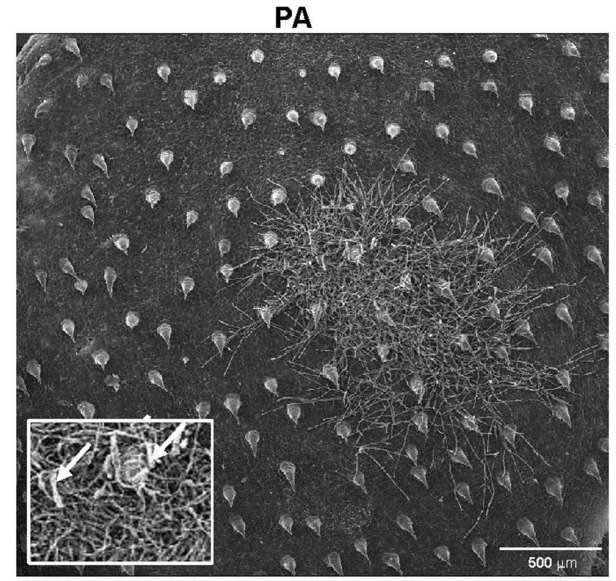

B
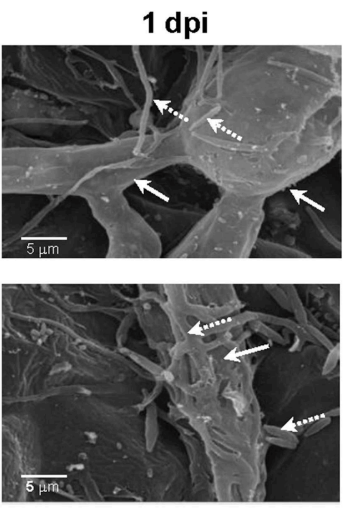

PA

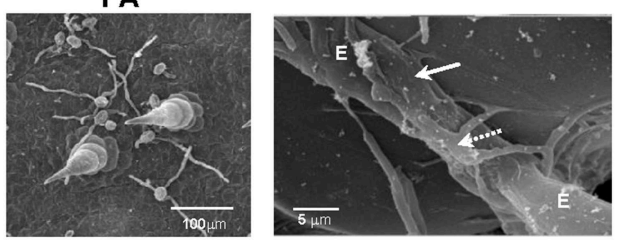

Control
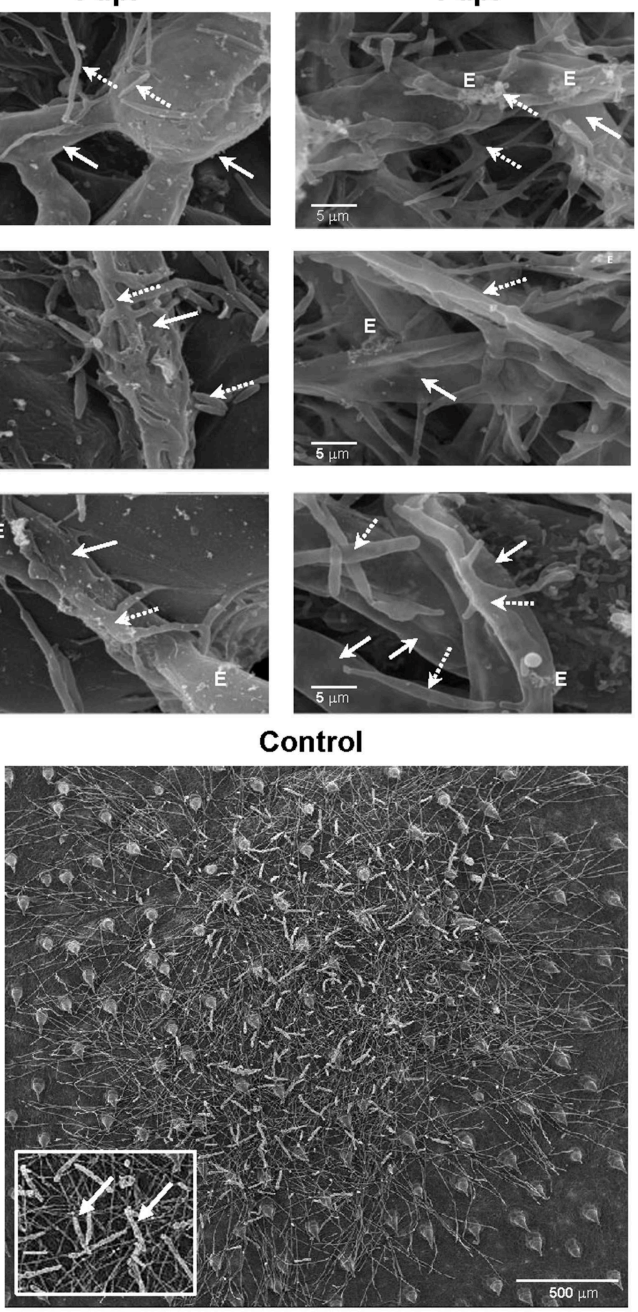

FIGURE 3 | P. aphidis-powdery mildew interactions on cucumber cotyledons. SEM microscopy of cucumber cotyledons treated with $P$. aphidis and infected with Podosphaera xanthii. (A) Cucumber cotyledons treated with $P$. aphidis 4 days post-infection with $P$. xanthii. (B) Closer look at the interaction of $P$. aphidis and $P$. xanthii mycelium and spores 1 and 4 days

post-infection with $P$. xanthii. Cucumber cotyledons treated with $P$. aphidis (PA) or with water (Control) 1 day post-inoculation (C) and 10 days post-inoculation with $P$. xanthii (D) (sporulation marked with white arrows). (A-C) P. xanthii mycelium and spores are indicated with white arrows and P. aphidis cells and hyphae with dashed arrows; E, extracellular matrix.

$21.8 \mathrm{~mm}$ as compared to $9.1 \mathrm{~mm}$ on TWA alone (Figure 6). These findings suggest that $P$. aphidis can secrete chitinase to utilize chitin as a carbon source.

\section{Discussion}

Fungal biocontrol agents are important for disease control and can provide a viable alternative for chemical-based pesticides. Yet the number of fungal biocontrol agents that are currently used for practical applications is minuscule as compared with the use of chemical-based agents. We recently identified a unique isolate of $P$. aphidis (isolate L12) from strawberry leaves associated with powdery mildew collapse and demonstrated that this isolate can reduce $B$. cinerea infection of tomato and Arabidopsis plants (Buxdorf et al., 2013a,b). That biocontrol effect against $B$. cinerea was found to proceed via a dual mode of action, antibiosis and induced resistance that is SA/NPR1- and JA/ETindependent (Buxdorf et al., 2013a,b). Here, we studied the ability of this isolate to control the growth of another pathogen. We demonstrated that $P$. aphidis can colonize healthy plant leaf surfaces and that it can proliferate on powdery mildew infected cucumber cotyledons (Figures 1-3, and Supplementary Figure 2), as was also demonstrated for its close relative Pseudozyma flocculosa, which can colonize cucumber leaves that have been inoculated with powdery mildew (Hammami et al., 2011).

The $P$. aphidis isolate studied in this work was found to control powdery mildew (Table 1) via parasitism (Figures 3-5) and 

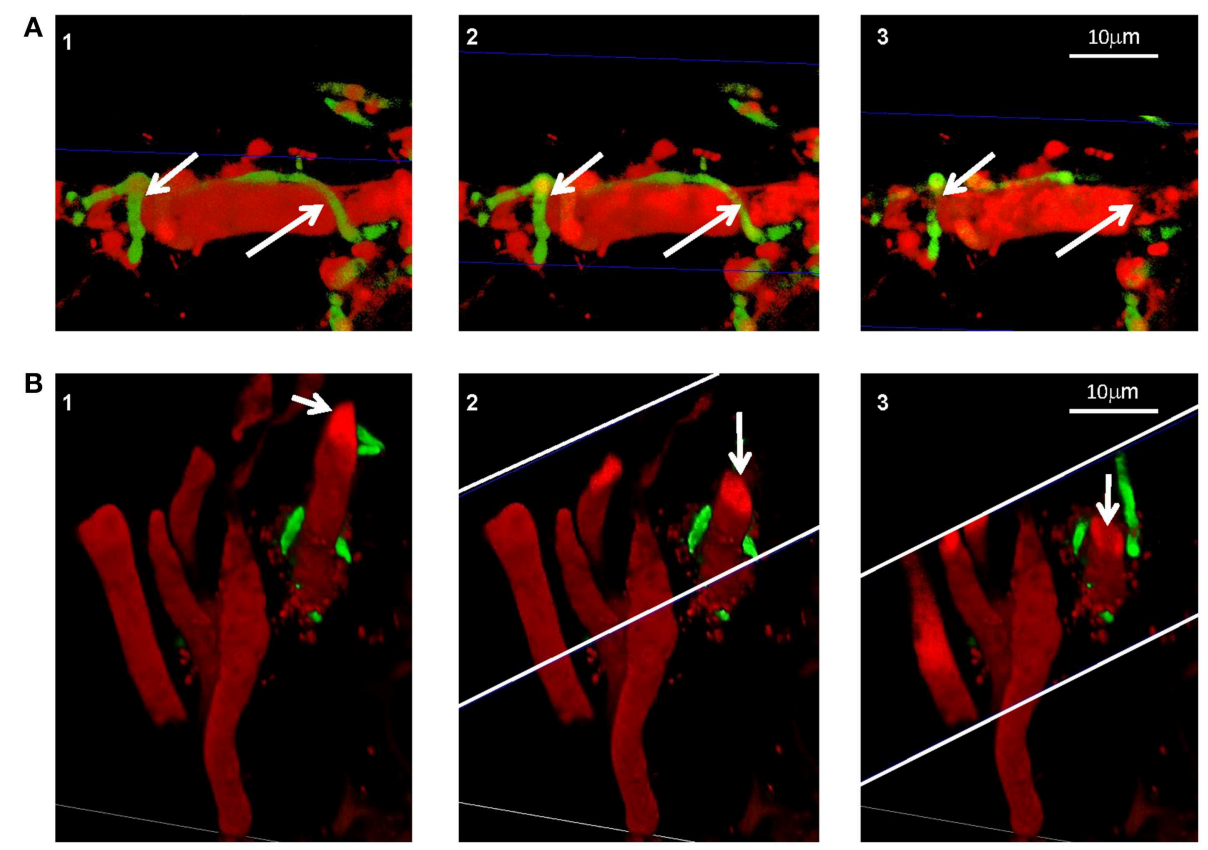

FIGURE 4 | $\boldsymbol{P}$, aphidis as an ectoparasite. Confocal microscopic analysis of cucumber cotyledons treated with propidium iodide 10 days after treatment with GFP-tagged $P$. aphidis (green) and 7 days after inoculation with P. xanthii (red). (A) Reconstructed 3D images demonstrating $P$. aphidis (green; marked with white arrows) coiling around the powdery mildew hyphae and cross-sections (marked with blue thin lines) demonstrating no fluorescence inside the powdery mildew hypha. See Supplemental Movie 1 for whole series of sections. (B) Reconstructed 3D cross-section images. The white thin lines marked the area of the cross-sections, while the white arrows point to the sectioned powdery mildew hypha. See Supplemental Movie 2 for whole series of sections. antibiosis (Table 2). This is in contrast to the findings reported in previous studies by Avis et al. (2001). The difference between our findings and those of Avis et al. (2001) is likely due to the different isolates used. It is particularly noteworthy that the application of $P$. aphidis prior to pathogen inoculation significantly reduced the severity of powdery mildew on greenhouse-grown cucumber plants with an efficacy of 75\% (Table 1). We and others have previously reported that applying a biocontrol agent before pathogen infection can indeed improve biocontrol activity (Filonow et al., 1996; Buxdorf et al., 2013a,b), but other reports have suggested otherwise (Chalutz and Wilson, 1990; Cook et al., 1997).

We demonstrated that $P$. aphidis occupies the same niches as powdery mildew (Figures 1-3), as also observed previously with B. cinerea (Buxdorf et al., 2013b) and similar to observations made with its close relative the biocontrol agent $P$. flocculosa in association with powdery mildew (Hammami et al., 2011). $P$. aphidis isolate L12 was also shown to have a dimorphic morphology, forming yeast-like structures and short pseudo-hyphae on plant surfaces or when interacting with $B$. cinerea (Buxdorf et al., 2013b). Here we demonstrated that $P$. aphidis mainly forms yeast-like structures on uninfected leaves and hyphae on infected tissue that lengthen with infection development (Figures 2, 3). Similarly, Hammami et al. (2010, 2011) demonstrated pseudohyphal growth of $P$. flocculosa under stress conditions as compared to yeast-like growth under control conditions (Hammami et al., 2010, 2011). In many other dimorphic fungi, the morphological choice of yeast or mycelium is associated with quorum sensing, inoculum size, stress conditions and secreted molecules (Hornby et al., 2001, 2004; Hogan, 2006; Nickerson et al., 2006; Berrocal et al., 2014). Since we did not observed coiling or the formation of long hyphae when $P$. aphidis interacted with $B$. cinerea, we assume that the interaction with powdery mildew triggers this yeast-mycelia transition, probably involving molecule secretion or other cues that activate gene expression and need to be further characterized. We demonstrated that $P$. aphidis attaches by coiling around the powdery mildew hyphae, forming a hyphal network. While we could observe strong attachments of $P$. aphidis to the powdery mildew hyphae and appressorium-like structures using SEM (Figure 3), we did not observed $P$. aphidis inside the powdery mildew hypha using confocal or TEM microscopy (Figures 4, 5 and Supplementary Movies 1, 2). This suggests that $P$. aphidis is an ectoparasite of $P$. xanthii, as also demonstrated with Trichoderma spp. on Pythium, Rhizoctonia solani, Sclerotium rolfsii, and Sclerotinia sclerotium (Chet et al., 1981; Elad et al., 1983; Hubbard et al., 1983; Inbar et al., 1996). Although we could not observe any penetration of $P$. aphidis into the powdery mildew hyphae (Figures 4, 5 and Supplementary Movies 1,2), we could demonstrate chitinase activity in vitro (Figure 6). It has been shown that attachment of an antagonist to a pathogen plays a major role in the former's biological activities, enabling cell wall degrading enzymes to be effective (Jones, 1994; Askary et al., 1997; Cook et al., 1997). 

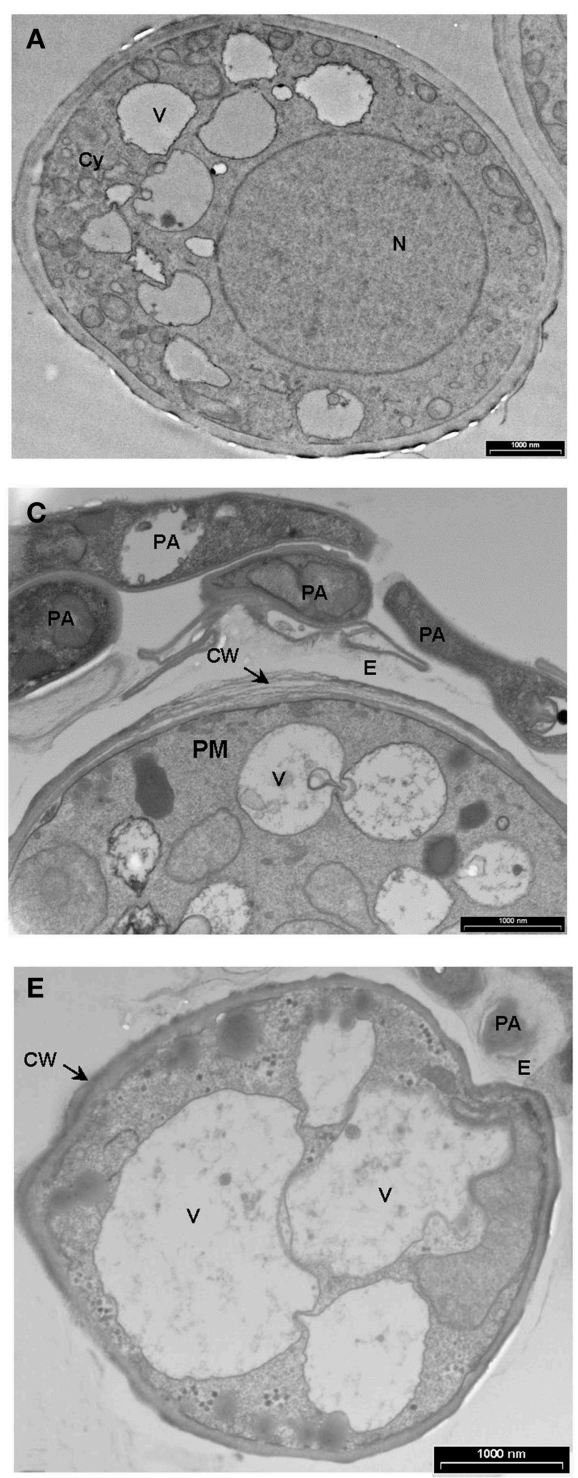

FIGURE 5 | Transmission electron micrographs depicting the interaction between $P$. Xanthii and $P$. aphidis on cucumber leaves. (A,B) Ultrastructure of $P$. xanthii (PM) hypha on cucumber leaves 8 days post-inoculation. Hyphal cells are surrounded by an intact cell wall (CW) and show a dense polyribosome-rich cytoplasm (Cy), with numerous organelles inside, including mitochondria $(M)$, nucleus $(N)$ and vacuoles $($ ). (C-G) Ultrastructure of $P$. xanthii and P. aphidis (PA)
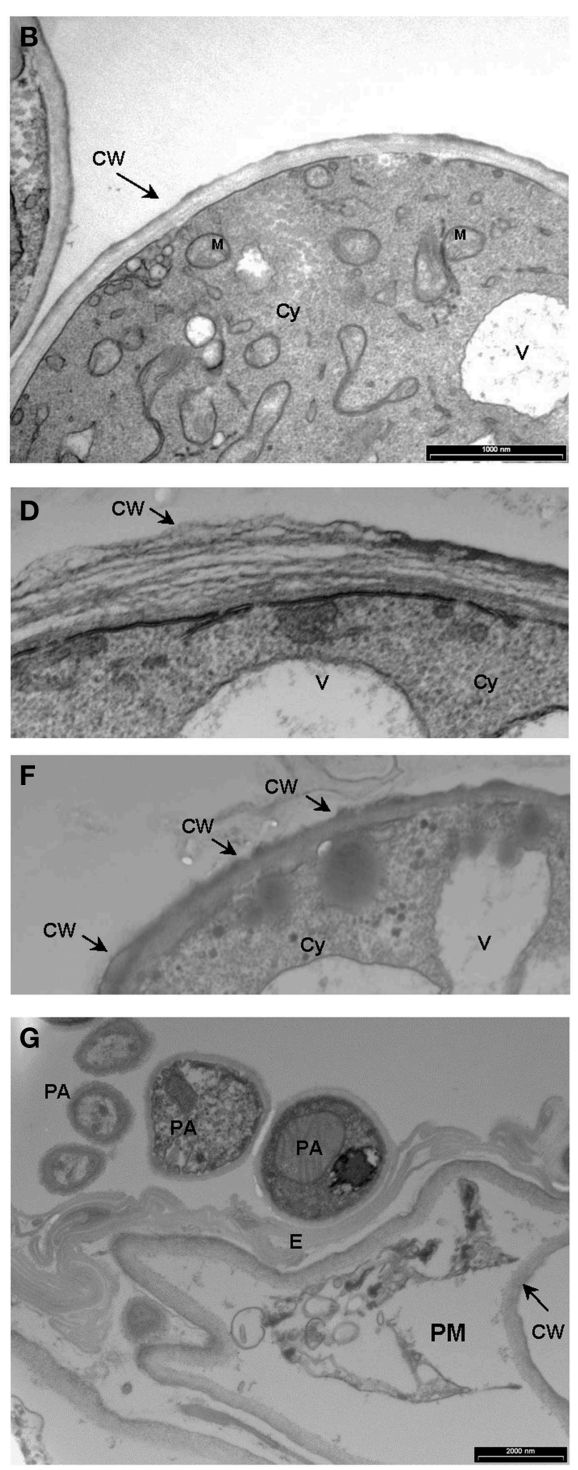

interactions on cucumber leaves 8 days post-inoculation and 11 days post-treatment with $P$. aphidis. (C) $P$. aphidis cells encircle the $P$. xanthii hyphae causing deformation of the cell wall (CW), also seen at higher magnification in (D). (E) Increased vacuolation is accompanied by deformation of the cell wall and disorganization of the cytoplasm, also seen at higher magnification in (F). (G) P. xanthii cells are markedly collapsed. E, extracellular matrix.
The abundance of $P$. aphidis on $P$. xanthii (Figures 1, 2), its coiling around P. xanthii as demonstrated by SEM (Figure 3), and its chitinase activity demonstrated in vitro (Figure 6), suggest that $P$. aphidis parasitizes the powdery mildew hyphae. $P$. aphidis probably disrupts the pathogen's tissue via the chitinase activity and releases the nutrients required for abundant growth of $P$. aphidis. Moreover we were able to demonstrate antibiosis of $P$. aphidis crude extract against $P$. xanthii in planta (Table 2). This might contribute to its biocontrol ability by damaging and even killing powdery mildew cells. This is the first case, as far as we know, that mycoparasitism is demonstrated as a mode of action of a yeast-like biocontrol agent against powdery mildew. The literature mostly describes antibiosis as a mode of action of yeast-like biocontrol agents such as $P$. flocculosa (Bélanger et al., 1994; Hajlaoui et al., 1994; Benyagoub et al., 1996; Avis and Belanger, 2001; Avis et al., 2001; Hammami et al., 2010, 2011) and Tilletiopsis species (Urquhart and Punja, 1997, 2002) against powdery mildew. While mycoparasitism against powdery mildew was demonstrated as a mode of action used by biocontrol fungi such as Veticillium lecanii (Askary et al., 1997, 1998) and 


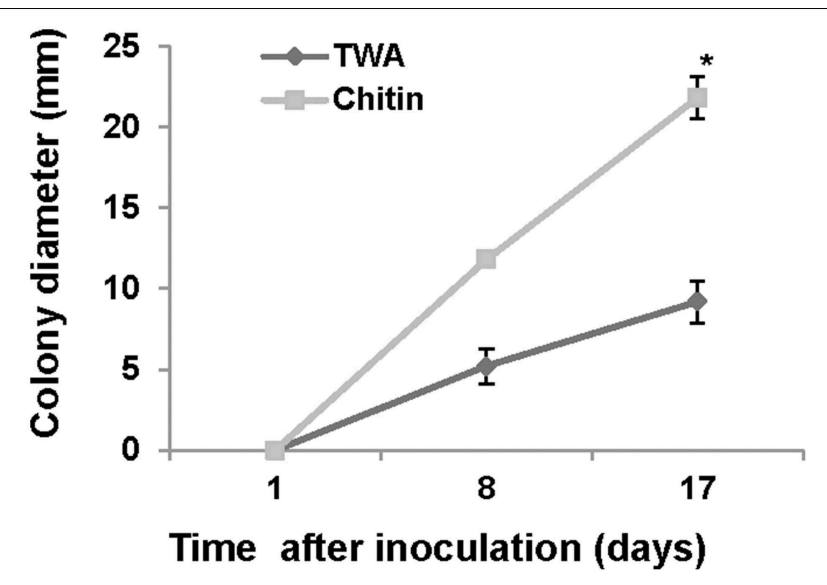

FIGURE 6 | Chitinase activity. Growth of $P$. aphidis on $0.1 \%$ chitin as compared to TWA. Averages of five samples are presented with standard-error bars. Asterisks indicate a significant difference as determined by Student's t-test; $P<0.05$.

TABLE 2 | Inhibition of spore germination by. $P$. aphidis crude extract.

\begin{tabular}{lc}
\hline Treatment & $\begin{array}{c}\text { Inhibition of spore } \\
\text { germination (\%) }\end{array}$ \\
\hline PA & $97.5 \pm 1.7^{*}$ \\
Control & $2.3 \pm 4.3$ \\
\hline
\end{tabular}

Percentage of spore inhibition after $24 \mathrm{~h}$ on cucumber cotyledon disks covered with $P$. aphidis crude extract (PA) or EtOAc (Control). Data represent the means \pm standard deviation. Value followed by an asterisk is significantly different from the control according to Student's $t$-test; $P<0.001 ; n=7$ replicates per treatment with 100 spores each.

by Ampelomyces quisiqualis on cucumber plants (Rotem et al., 1999).

The chitinase activity of $P$. aphidis L12 (Figure 6), is supported also by recently released DNA sequence of $P$. aphidis (isolate DSM 70725) demonstrating one chitinase gene and two other candidate genes that are related to chitinase (Lorenz et al., 2014). Furthermore, the sequenced isolate contains one extracellular aspartic proteinase and eight potential glucanases (Lorenz et al., 2014); these cell wall-degrading enzymes might be involved in degradation of the pathogen cell wall, but the availability and intactness of those genes and their protein activity must be further characterized in our isolate. Furthermore, genome and transcriptome analysis of the biocontrol agent $P$. flocculosa demonstrated differences from the pathogenic related fungi U. maydis

\section{References}

Allen, T. W., Quayyum, H. A., Burpee, L. L., and Buck, J. W. (2004). Effect of foliar disease on the epiphytic yeast communities of creeping bentgrass and tall fescue. Can. J. Microbiol. 50, 853-860. doi: 10.1139/w04-073

Askary, H., Benhamou, N., and Brodeur, J. (1997). Ultrastructural and cytochemical investigations of the antagonistic effect of Verticillium lecanii on cucumber powdery mildew. Phytopathology 87, 359-368. doi: 10.1094/PHYTO.1997.87.3.359 in genes related to fungal cell wall degradation and other gene families related to $P$. flocculosa's epiphytic and antagonistic characteristics, such as lipases, chitinases and chitin binding proteins (Lefebvre et al., 2013).

The released sequences of the genomes of Pseudozyma spp. provide further support for antibiosis as they reveal the presence of gene clusters regulating synthesis of glycolipids, some of which have an antibiosis ability (Lefebvre et al., 2013; Morita et al., 2013a, 2014; Lorenz et al., 2014; Saika et al., 2014). Flocculosin, synthesized by $P$. flocculosa is an example of such glycolipid (Teichmann et al., 2007, 2011a,b). We speculate $P$. aphidis isolate L12 also has the ability to produce glycolipid/s with antibiosis ability. However, antibiosis as a mode of action in vivo is still questionable since $U$. maydis, which synthesize ustilagic acid, an antifungal compound very similar to flocculosin, does not have any antagonistic effect against powdery mildew (Hammami et al., 2011).

Collectively, our data show that the P. aphidis isolate L12 has potential for use as a biocontrol agent against powdery mildew via mycoparasitism. We also suggest antibiosis as a possible mechanism based on our observation that spore-germination of powdery mildew is inhibited in planta by the crude extract of metabolites of $P$. aphidis. We show morphological yeast-to-hypha transition of $P$. aphidis that parasitize the powdery mildew. However, to extend our knowledge, it is important to identify the cues causing $P$. aphidis dimorphism in association with $P$. xanthii.

\section{Author Contributions}

ML designed the experiments. AG, KB, CC, RH, and AD performed the experiments. EZ preform the confocal microscopy analysis. ML analyzed the results and wrote the manuscript. All authors read and approved the final manuscript.

\section{Acknowledgments}

We thank Prof. Regine Khamann from the Max Plank Institute (Germany) for providing us the GFP construct. This work was supported by the Chief Scientist of the Ministry of Agriculture, Israel, grant 823-0209-14.

\section{Supplementary Material}

The Supplementary Material for this article can be found online at: http://www.frontiersin.org/journal/10.3389/fpls.2015. 00132/abstract 
Avis, T. J., Caron, S. J., Boekhout, T., Hamelin, R. C., and Belanger, R. R. (2001). Molecular and physiological analysis of the powdery mildew antagonist Pseudozyma flocculosa and related fungi. Phytopathology 91, 249-254. doi: 10.1094/PHYTO.2001.91.3.249

Barnett, J. A., Payne, R. W., and Yarrow, D. (2000). Yeasts: Characteristics and Identification. Cambridge: Cambridge University Press

Begerow, D., Bauer, R., and Boekhout, T. (2000). Phylogenetic placements of ustilaginomycetous anamorphs as deduced from nuclear LSU rDNA sequences. Mycol. Res. 104, 53-60. doi: 10.1017/S0953756299001161

Bélanger, R. R., Labbé, C., and Jarvis, W. R. (1994). Commercial-scale control of rose powdery mildew with a fungal antagonist. Plant Dis. 78, 420-424. doi: 10.1094/PD-78-0420

Bélanger, R. R., Bushnell, W. R., Dik, A. J., and Carver, T. L. W. (2002). The Powdery Mildews: A Comprehensive Treatise. St. Paul, MN: American Phytopatholgical Society Press.

Benyagoub, M., Willemot, C., and Bélanger, R. R. (1996). Influence of a subinhibitory dose of antifungal fatty acids from Sporothrix flocculosa on cellular lipid composition in fungi. Lipids 31, 1077-1082. doi: 10.1007/BF02522465

Berrocal, A., Oviedo, C., Nickerson, K. W., and Navarrete, J. (2014). Quorum sensing activity and control of yeast-mycelium dimorphism in Ophiostoma floccosum. Biotechnol. Let. 36, 1503-1513. doi: 10.1007/s10529-014-1514-5

Bleve, G., Grieco, F., Cozzi, G., Logrieco, A., and Visconti, A. (2006). Isolation of epiphytic yeasts with potential for biocontrol of Aspergillus carbonarius and A. niger on grape. Int. J. Food Microbiol. 108, 204-209. doi: 10.1016/j.ijfoodmicro.2005.12.004

Boekhout, T. (1995). Pseudozyma Bandoni emend. Boekhout, a genus for yeastlike anamorphs of Ustilaginales. Gen. Appl. Microbiol. 41, 359-366. doi: 10.2323/jgam.41.359

Buck, J. W., and Burpee, L. L. (2002). The effects of fungicides on the phylloplane yeast populations of creeping bentgrass. Can. J. Microbiol. 48, 522-529. doi: 10.1139/w02-050

Buxdorf, K., Rahat, I., Gafni, A., and Levy, M. (2013a). The epiphytic fungus Pseudozyma aphidis induces jasmonic acid- and salicylic acid/nonexpressor of PR1independent local and systemic resistance. Plant Physiol. 161, 2014-2022. doi: 10.1104/pp.112.212969

Buxdorf, K., Rahat, I., and Levy, M. (2013b). Pseudozyma aphidis induces ethylene-independent resistance in plants. Plant Signal. Behav. 8:e26273. doi: $10.4161 /$ psb. 26273

Chalutz, E., and Wilson, C. L. (1990). Postharvest biocontrol of green and blue mold and sour rot of citrus fruit by Debaryomyces hansenii. Plant Dis. 74, 134-137. doi: 10.1094/PD-74-0134

Chet, I., Harman, G., and Baker, R. (1981). Trichoderma hamatum: its hyphal interactions with Rhizoctonia solani and Pythium spp. Microb. Ecol. 7, 29-38. doi: 10.1007/BF02010476

Chuartzman, S. G., Nevo, R., Shimoni, E., Charuvi, D., Kiss, V., Ohad, I., et al. (2008). Thylakoid membrane remodeling during state transitions in Arabidopsis. Plant Cell 20, 1029-1039. doi: 10.1105/tpc.107.055830

Cook, D. W. M., Long, P. G., Ganesh, S., and Cheah, L. H. (1997). Attachment microbes antagonistic against Botrytis cinerea-biological control and scanning electron microscope studies in vivo. Ann. Appl. Biol. 131, 503-518. doi: 10.1111/j.1744-7348.1997.tb05177.x

Denholm, I., and Rowland, M. W. (1992). Tactics for managing pesticide resistance in arthropods: theory and practice. Annu. Rev. Entomol. 37, 91-112. doi: 10.1146/annurev.en.37.010192.000515

Dik, A. J., Verhaar, M. A., and Bélanger, R. R. (1998). Comparison of three biological control agents against cucumber powdery mildew (Sphaerotheca fuliginea) in semi-commercial-scale glasshouse trials. Eur. J. Plant Pathol. 104, 413-423. doi: 10.1023/A:1008025416672

Elad, Y., Chet, I., Boyle, P., and Henis, Y. (1983). Parasitism of Trichoderma spp. on Rhizoctonia solani and Sclerotium rolfsii-scanning electron microscopy and fluorescence microscopy. Phytopathology 73, 85-88. doi: 10.1094/Phyto$73-85$

Elad, Y., and Freeman, S. (2002). "Biological control of fungal plant pathogens," in The Mycota, A Comprehensive Treatise on Fungi as Experimental Systems for Basic and Applied Research. XI. Agricultural Applications, ed F. Kempken (Heidelberg: Springer), 93-109

Fernandez, N. V., Mestre, M. C., Marchelli, P., and Fontenla, S. B. (2012). Yeast and yeast-like fungi associated with dry indehiscent fruits of Nothofagus nervosa in
Patagonia, Argentina. FEMS Microbiol. Ecol. 80, 179-192. doi: 10.1111/j.15746941.2011.01287.x

Filonow, A. B., Vishniac, H. S., Anderson, J. A., and Janisiewicz, W. J. (1996). Biological control of Botrytis cinerea in apple by yeasts from various habitats and their putative mechanisms of antagonism. Biol. Cont. 7, 212-220. doi: 10.1006/bcon. 1996.0086

Hajlaoui, M. R., Traquair, J. A., Jarvis, W. R., and Bélanger, R. R. (1994). Antifungal activity of extracellular metabolites produced by Sporothrix flocculosa. Biocontrol Sci. Technol. 4, 229-237. doi: 10.1080/09583159409355331

Hammami, W., Castro, C. Q., Remus-Borel, W., Labbe, C., and Belanger, R. R. (2011). Ecological basis of the interaction between Pseudozyma flocculosa and powdery mildew fungi. Appl. Environ. Microbiol. 77, 926-933. doi: 10.1128/AEM.01255-10

Hammami, W., Chain, F., Michaud, D., and Bélanger, R. R. (2010). Research Proteomic analysis of the metabolic adaptation of the biocontrol agent Pseudozyma flocculosa leading to glycolipid production. Proteome Sci. 8:7 doi: 10.1186/1477-5956-8-7

Henninger, W., and Windisch, S. (1975). Pichia lindnerii sp. n., a new methanol assimilating yeast from soil. Arch. Microbiol. 105, 47-48. doi: 10.1007/BF004 47111

Hogan, D. A. (2006). Talking to themselves: autoregulation and quorum sensing in fungi. Eukaryot Cell 5, 613-619. doi: 10.1128/EC.5.4.613-619.2006

Hollomon, D., Wheeler, I., Bélanger, R., Bushnell, W., Dik, A., and Carver, T. (2002). Controlling powdery mildews with chemistry. St. Paul, MN: American Phytopathology Society Press.

Hornby, J. M., Jacobitz-Kizzier, S. M., McNeel, D. J., Jensen, E. C., Treves, D. S., and Nickerson, K. W. (2004). Inoculum size effect in dimorphic fungi: extracellular control of yeast-mycelium dimorphism in Ceratocystis ulmi. Appl. Environ. Microbiol. 70, 1356-1359. doi: 10.1128/AEM.70.3.1356-1359.2004

Hornby, J. M., Jensen, E. C., Lisec, A. D., Tasto, J. J., Jahnke, B., Shoemaker, R., et al. (2001). Quorum sensing in the dimorphic fungus Candida albicans is mediated by farnesol. Appl. Environ. Microbiol. 67, 2982-2992. doi: 10.1128/AEM.67.7.2982-2992.2001

Horsfall, J. G., and Barratt, R. W. (1945). An improved grading system for measuring plant disease. Phytopathology 35, 655.

Hubbard, J., Harman, G., and Hadar, Y. (1983). Effect of soilborne Pseudomonas spp. on the biological control agent, Trichoderma hamatum. on pea seeds. Phytopathology 73, 655-659. doi: 10.1094/Phyto-73-655

Inbar, J., Menendez, A., and Chet, I. (1996). Hyphal interaction between Trichoderma harzianum and Sclerotinia sclerotiorum and its role in biological control. Soil Biol. Biochem. 28, 757-763. doi: 10.1016/0038-0717(96)00010-7

Jacobsen, B. (2006). "Biological control of plant disease by phyllosphere applied biological control agents," in Microbial Ecology, Aerial Plant Surfaces, eds M. Bailey, A. Lilley, T. Timms-Wilson, and P. Spencer-Philips (London: CABI international), 133-147.

Jones, E. (1994). Fungal adhesion. Mycol. Res. 98, 961-981. doi: 10.1016/S09537562(09)80421-8

Kiss, L. (2003). A review of fungal antagonists of powdery mildews and their potential as biocontrol agents. Pest Manag. Sci. 59, 475-483. doi: 10.1002/ps.689

Lefebvre, F., Joly, D. L., Labbé, C., Teichmann, B., Linning, R., Belzile, F., et al. (2013). The transition from a phytopathogenic smut ancestor to an anamorphic biocontrol agent deciphered by comparative whole-genome analysis. Plant Cell 25, 1946-1959. doi: 10.1105/tpc.113.113969

Leroux, P., Fritz, R., Debieu, D., Albertini, C., Lanen, C., Bach, J., et al. (2002). Mechanisms of resistance to fungicides in field strains of Botrytis cinerea. Pest Manag. Sci. 58, 876-888. doi: 10.1002/ps.566

Lorenz, S., Guenther, M., Grumaz, C., Rupp, S., Zibek, S., and Sohn, K. (2014). Genome Sequence of the Basidiomycetous fungus Pseudozyma aphidis DSM70725, an efficient producer of biosurfactant mannosylerythritol lipids. Genome Announc. 2. doi: 10.1128/genomeA.00053-14

McGrath, M. T. (2001). Fungicide resistance in cucurbit powdery mildew: experiences and challenges. Plant Dis. 85, 236-245. doi: 10.1094/PDIS.2001.85.3.236

Morita, T., Fukuoka, T., Imura, T., and Kitamoto, D. (2013a). Accumulation of cellobiose lipids under nitrogen-limiting conditions by two ustilaginomycetous yeasts, Pseudozyma aphidis and Pseudozyma hubeiensis. FEMS Yeast Res. 13, 44-49. doi: 10.1111/1567-1364.12005

Morita, T., Koike, H., Hagiwara, H., Ito, E., Machida, M., Sato, S., et al. (2014). Genome and transcriptome analysis of the Basidiomycetous yeast Pseudozyma 
antarctica producing extracellular glycolipids, mannosylerythritol lipids. PLoS ONE 9:e86490. doi: 10.1371/journal.pone.0086490

Morita, T., Koike, H., Koyama, Y., Hagiwara, H., Ito, E., Fukuoka, T., et al. (2013b). Genome sequence of the basidiomycetous yeast Pseudozyma antarctica T-34, a producer of the glycolipid biosurfactants mannosylerythritol lipids. Genome Announc. 1:e0006413. doi: 10.1128/genomeA.00064-13

Nickerson, K. W., Atkin, A. L., and Hornby, J. M. (2006). Quorum sensing in dimorphic fungi: farnesol and beyond. Appl. Environ. Microbiol. 72, 3805-3813. doi: 10.1128/AEM.02765-05

Paz, Z., Burdman, S., Gerson, U., and Sztejnberg, A. (2007). Antagonistic effects of the endophytic fungus Meira geulakonigii on the citrus rust mite Phyllocoptruta oleivora. J. Appl. Microbiol. 103, 2570-2579. doi: 10.1111/j.13652672.2007.03512.x

Perez-Garcia, A., Romero, D., Fernandez-Ortuno, D., Lopez-Ruiz, F., De Vicente, A., and Tores, J. A. (2009). The powdery mildew fungus Podosphaera fusca (synonym Podosphaera xanthii), a constant threat to cucurbits. Mol. Plant Pathol. 10, 153-160. doi: 10.1111/j.1364-3703.2008.00527.x

Pusey, P. L., Stockwell, V. O., and Mazzola, M. (2009). Epiphytic bacteria and yeasts on apple blossoms and their potential as antagonists of Erwinia amylovora. Phytopathology 99, 571-581. doi: 10.1094/PHYTO-99-5-0571

Raupach, G. S., Liu, L., Morphy, J. F., Tuzun, S., and Kloepper, J. W. (1996). Induced systemic resistance in cucumber and tomato against cucumber mosaic cucumovirus using plant growth-promoting rhizobacteria (PGPR). Plant Dis. 80, 891-894. doi: 10.1094/PD-80-0891

Robiglio, A., Sosa, M. C., Lutz, M. C., Lopes, C. A., and Sangorrin, M. P. (2011). Yeast biocontrol of fungal spoilage of pears stored at low temperature. Int. J. Food Microbiol. 147, 211-216. doi: 10.1016/j.ijfoodmicro.2011. 04.007

Rotem, Y., Yarden, O., and Sztejnberg, A. (1999). The mycoparasite Ampelomyces quisqualis expresses exgA encoding an exo- $\beta$-1, 3-glucanase in culture and during mycoparasitism. Phytopathology 89, 631-638. doi: 10.1094/PHYTO.1999. 89.8.631

Saika, A., Koike, H., Hori, T., Fukuoka, T., Sato, S., Habe, H., et al. (2014). Draft genome sequence of the yeast Pseudozyma antarctica type strain JCM10317, a producer of the glycolipid biosurfactants, mannosylerythritol lipids. Genome Announc. 2:e00878-14. doi: 10.1128/genomeA.00878-14
Shoresh, M., Harman, G. E., and Mastouri, F. (2010). Induced systemic resistance and plant responses to fungal biocontrol agents. Annu. Rev. Phytopathol. 48, 21-43. doi: 10.1146/annurev-phyto-073009-114450

Teichmann, B., Labbé, C., Lefebvre, F., Bölker, M., Linne, U., and Bélanger, R. R. (2011a). Identification of a biosynthesis gene cluster for flocculosin a cellobiose lipid produced by the biocontrol agent Pseudozyma flocculosa. Mol. Microbiol. 79, 1483-1495. doi: 10.1111/j.1365-2958.2010.07533.x

Teichmann, B., Lefebvre, F., Labbé, C., Bölker, M., Linne, U., and Bélanger, R. R. (2011b). Beta hydroxylation of glycolipids from Ustilago maydis and Pseudozyma flocculosa by an NADPH-dependent $\beta$-hydroxylase. Appl. Environ. Microbiol. 77, 7823-7829. doi: 10.1128/AEM.05822-11

Teichmann, B., Linne, U., Hewald, S., Marahiel, M. A., and Bölker, M. (2007). A biosynthetic gene cluster for a secreted cellobiose lipid with antifungal activity from Ustilago maydis. Mol. Microbiol. 66, 525-533. doi: 10.1111/j.13652958.2007.05941.x

Urquhart, E. J., and Punja, Z. K. (2002). Hydrolytic enzymes and antifungal compounds produced by Tilletiopsis species, phyllosphere yeasts that are antagonists of powdery mildew fungi. Can. J. Microbiol. 48, 219-229. doi 10.1139/w02-008

Urquhart, E., and Punja, Z. (1997). Epiphytic growth and survival of Tilletiopsis pallescens, a potential biological control agent of Sphaerotheca fuliginea, on cucumber leawes. Can. J. Bot. 75, 892-901. doi: 10.1139/b97-099

Weigel, D., and Glazebrook, J. (2002). Arabidopsis: A Laboratory Manual. Cold Spring Harbor, NY: Cold Spring Harbor Laboratory Press.

Conflict of Interest Statement: The authors declare that the research was conducted in the absence of any commercial or financial relationships that could be construed as a potential conflict of interest.

Copyright (c) 2015 Gafni, Calderon, Harris, Buxdorf, Dafa-Berger, Zeilinger-Riechert and Levy. This is an open-access article distributed under the terms of the Creative Commons Attribution License (CC BY). The use, distribution or reproduction in other forums is permitted, provided the original author(s) or licensor are credited and that the original publication in this journal is cited, in accordance with accepted academic practice. No use, distribution or reproduction is permitted which does not comply with these terms. 